Electronics 2012, 1, 1-2; doi:10.3390/electronics1010001

OPEN ACCESS

electronics

ISSN 2079-9292

www.mdpi.com/journal/electronics

\title{
Editorial
}

\section{Electronics - A New Multidisciplinary Open Access Journal}

\section{Mostafa Bassiouni}

Editor-in-Chief of Electronics, Department of Electrical Engineering and Computer Science, University of Central Florida, Orlando, FL 32816, USA; E-Mail: bassi@cs.ucf.edu;

Tel.: +1-407-823-2837

Received: 27 December 2011 / Accepted: 28 December 2011 / Published: 28 December 2011

The proliferation of electronic devices has profoundly affected all aspects of modern life. Large populations of people worldwide are now acclimated to the use of modern electronic devices on a daily basis. Giant industrial corporations, commercial companies and small businesses all use a variety of computing, communications and electronic devices to increase their productivity, enhance market research and improve customer support and satisfaction.

To cope with the rapidly changing world of electronic technologies, I am pleased to introduce Electronics, a peer-reviewed open access journal designed to appeal to a diverse audience of research scientists in academia and industry as well as practitioners, developers, and graduate students in all areas related to electronics.

Electronics is envisioned as a multidisciplinary journal whose topics of interest include but are not limited to computer and information technology; wireless and mobile communications; instrumentation, measurement and testing; microwave techniques and devices; satellite communication systems; photonics and optical communications; radar and sonar technology; semiconductors and signal processing; control and embedded systems; and biomedical electronics.

An excellent example of a single electronic device that has benefited from technological breakthroughs in many of the above areas is the smartphone. A modern smartphone coming out these days can easily incorporate an impressive host of electronic features including a dual-core processor, chips for two or more SIM cards, WiFi interface for wireless Internet connectivity, touch screen for augmented reality, GPS for geo-location tracking, camera with CMOS sensor for video recording and mobile video conferencing, Bluetooth for connectivity with other wireless devices, Java platform for developing and running software applications, and above all a sophisticated communication technology such as spread 
spectrum for cellular bandwidth access. Smartphones keep getting smarter and smarter and they could evolve in the not-too-distant future to incorporate a variety of new sensors for measuring temperature, ambient light, air quality, levels of hazardous chemicals, carbon monoxide build-ups, and all other types of data that will enable a distributed sensing revolution that is set to sweep the world.

I am honored to work with the MDPI Publisher and an excellent group of editorial board members in launching the Electronics journal. We invite scientists from all fields of electronics to publish their experimental and theoretical results in our new journal and submit proposals for special issues of the journal on selected topics of interest. We also welcome your feedback and suggestions on how to improve this journal and make it a success. Through your active participation, we hope to provide the readership of Electronics with up-to-date coverage of high-quality research, cutting-edge developments, and timely reviews of current and emerging technologies related to the broad field of electronics.

(C) 2012 by the authors; licensee MDPI, Basel, Switzerland. This article is an open access article distributed under the terms and conditions of the Creative Commons Attribution license (http://creativecommons.org/licenses/by/3.0/). 